\title{
Contributing to WUDAPT: A Local Climate Zone Classification of Two Cities in Ukraine
}

\author{
Olha Danylo, Linda See, Benjamin Bechtel, \\ Dmitry Schepaschenko, and Steffen Fritz
}

\begin{abstract}
Local climate zones (LCZs) divide the urban landscape into homogeneous types based on urban structure (i.e., morphology of streets and buildings), urban cover (i.e., permeability of surfaces), construction materials, and human activities (i.e., anthropogenic heat). This classification scheme represents a standardized way of capturing the basic urban form of cities and is currently being applied globally as part of the world urban database and portal tools (WUDAPT) initiative. This paper assesses the transferability of the $\mathrm{LCZ}$ concept to two Ukrainian cities, i.e., Kyiv and Lviv, which differ in urban form and topography, and considers three ways to validate and verify this classification scheme. An accuracy of $64 \%$ was achieved for Kyiv using an independent validation dataset while a comparison of the LCZ maps with the GlobeLand30 land cover map resulted in a match that was greater than $\mathbf{7 5 \%}$ for both cities. There was also good correspondence between the urban classes in the $L C Z$ maps and the urban points of interest in OpenStreetMap (OSM). However, further research is still required to produce a standardized validation protocol that could be used on a regular basis by contributors to WUDAPT to help produce more accurate LCZ maps in the future.
\end{abstract}

Index Terms-GlobeLand30, Landsat, local climate zones (LCZs), OpenStreetMap (OSM), remote sensing, Ukraine, urban areas.

$\mathbf{L}$ OCAL climate zones (LCZs) were developed by [1] as a way of dividing cities into different homogenous thermal regimes for the purpose of sitting weather stations, making representative temperature measurements and for providing urban climate models with a range of possible values for different types of model parameters, e.g., sky view factor and building surface fraction. LCZs are also useful for studying the urban heat island (UHI) effect, where increased temperatures are experienced relative to more rural areas [2]. More recently, the LCZ classification scheme has moved beyond its original purpose and is now recognized as a valuable way of characterizing the urban form and function of cities in a standardized way. The LCZ classification system consists of 10 urban classes, which can be characterized by urban structure (i.e., the morphology

Manuscript received July 10, 2015; revised March 01, 2016; accepted March 04, 2016. This work was supported in part by the Ernst Mach Grant, Austrian Exchange Service (OeAD-GmbH), Centre for International Cooperation and Mobility (ICM) and in part by the EU-funded ERC CrowdLand Grant 617754.

O. Danylo, L. See, D. Schepaschenko, and S. Fritz are with the International Institute for Applied Systems Analysis, Laxenburg 2361, Austria (e-mail: danylo@iiasa.ac.at; see@iiasa.ac.at; schepd@iiasa.ac.at; fritz@iiasa.ac.at).

B. Bechtel is with the University of Hamburg, Hamburg 20148, Germany (e-mail: benjamin.bechtel@uni-hamburg.de).

Color versions of one or more of the figures in this paper are available online at http://ieeexplore.iee.org.

Digital Object Identifier 10.1109/JSTARS.2016.2539977 of the streets and buildings), urban cover (i.e., permeability and vegetation/built fraction), urban fabric (i.e., the materials), and human activity (i.e., anthropogenic heating). The other seven classes within this scheme are pure, natural land cover types such as forest and water. A list of these classes is provided in Table I and more details can be found in [1]. The LCZs are generic enough that they should capture the main types of urban form globally (although this has yet to be fully tested) while providing a culturally neutral framework for characterizing the structure of cities.

The Urban Atlas, which is produced by the European Environment Agency as part of the Copernicus land monitoring program [3], represents a detailed urban classification but it is only available for large cities in European Union member countries. The urban types in the LCZ scheme are also more detailed than the urban fabric classes of the Urban Atlas. No other detailed urban classification exists that has been applied globally. The world urban database and access portal tools (WUDAPT) initiative (http://www.wudapt.org) is working toward the goal of mapping the LCZs of all major cities globally [4], [5].

There is a considerable literature emerging on the use of remote sensing to classify cities according to urban structure types (USTs) [6]-[8], also referred to as urban morphology types [9] and urban structural units [10]. However, as pointed out in [6], most of the previous studies have analyzed only one city with little thought for transferability to other areas. Each has their own classification scheme, which renders multicity comparisons impossible. Moreover, many of the methods use imagery that is not openly available as well as additional data such as building heights and footprints that are difficult to obtain globally. The WUDAPT philosophy is based on the use of data that are freely available and can be processed in a simple workflow using free software for any city in the world. Numerous multispectral, thermal, and morphological features as well as machine learning methods have been tested for discrimination of LCZs [11] and subsequently a workflow based on Landsat imagery and random forest has been developed by [11] and [12] and implemented in SAGA. Single studies have applied the method to cities with different climatic and cultural backgrounds including Khartoum in this Special Issue [13]. However, it has yet to be further tested and validated on other cities than those previously reported, i.e., Dublin, Houston, and Hamburg. Although building heights and building densities differ between the urban classes, it is possible to use spectral differences in urban materials and cover to differentiate urban structure, negating 
TABLE I

LCZ Classes [1]

\begin{tabular}{|c|l|c|l|}
\hline LCZ & Urban classes & LCZ & Natural classes \\
\hline 1 & Compact high-rise & A & Dense trees \\
\hline 2 & Compact mid-rise & B & Scattered trees \\
\hline 3 & Compact low-rise & C & Bush, scrub \\
\hline 4 & Open high-rise & D & Low plants \\
\hline 5 & Open mid-rise & E & Bare rock or paved \\
\hline 6 & Open low-rise & F & Bare soil or sand \\
\hline 7 & Lightweight low-rise & G & Water \\
\hline 8 & Large low-rise & & \\
\hline 9 & Sparsely built & & \\
\hline 10 & Heavy industry & & \\
\hline
\end{tabular}

the need for very high resolution data that are required, e.g., for USTs.

The aim of this paper is to further test this Landsat-based LCZ workflow on two large cities in Ukraine: Kyiv and Lviv, which differ in terms of urban structure and topography. These LCZ maps will provide a contribution to WUDAPT while also considering issues such as transferability of the methodology and independent validation, which has not been addressed previously in [12]. In particular, we use an independent stratified sample as well as additional datasets including OpenStreetMap (OSM) and the GlobeLand30 land cover product to validate the LCZ classification.

\section{STUdy AREA}

Two cities in Ukraine were chosen: Kyiv and Lviv; their locations are shown in Fig. 1. The choice of locations was based on possessing local knowledge of the urban landscape of these two cities. Local knowledge has been identified by [12] as a critical element in developing an LCZ classification. This is primarily because urban experts know their own cities well and are, therefore, the best placed to create the training areas for the LCZ classification. Validation is also aided by good local knowledge, which is used when comparing the resulting LCZ maps with very high resolution imagery in Google Earth. A brief description of these two cities is provided below.

Kyiv is the capital of Ukraine. This city dates back to at least the ninth century and has long been a city of importance; it had a population similar to Paris by the year 1200 [14]. With a population of around 2.87 million people in 2014 [15], it is the largest city in Ukraine and the eighth largest in Europe [16]. Kyiv is located in the northern part of the country on the Dnipro (or Dnieper) River with an area of around $839 \mathrm{~km}^{2}$ and an average elevation of $179 \mathrm{~m}$ [17]. The river cuts the city into two parts with the center located on the western bank of the river.

Lviv is located in the western part of Ukraine and was founded in the middle of the 13th century [18]. The city is much smaller than Kyiv, with a population of around $730 \mathrm{~K}$ and an area of $182 \mathrm{~km}^{2}$. It is the seventh largest city in Ukraine. The city has an average elevation of $289 \mathrm{~m}$, with the highest hill (412 $\mathrm{m}$ ) on the northern part of the city.

As the capital of Ukraine, Kyiv is six times larger in area than Lviv and is an agglomeration of surrounding satellite urban areas, reflecting a large commuter population, so has quite a different layout compared to Lviv. The street layout of Kyiv is an irregular grid like structure, probably reflecting the Roman 133 influence, whereas Lviv has an irregular street layout, where the 134 main streets follow the original underground water ways [19]. 135 Despite the difference in sizes and populations, the average liv- 136 ing area per person is similar [15], [20]. Both cities also have 137 different topographic characteristics, which will affect the local 138 climate. Moreover, their histories are quite different, i.e., Lviv 139 was part of the Austro-Hungarian empire, whereas Kyiv was 140 part of the Russian empire so the urban form, i.e., the building 141 architecture and street layouts, differs.

Both cities have a humid continental climate with cold win- 143 ters (Köppen-Geiger classification of Dfb). The average high 144 temperature in summer is around $25^{\circ} \mathrm{C}$ but extremes of almost 145 $40{ }^{\circ} \mathrm{C}$ have been recorded in the past. The cities are subject to 146 UHI effects, but these are exacerbated during extreme events.

\section{Materials And Methods}

\section{A. Data Inputs}

Landsat 8 imagery was downloaded from the US Geological 150 Survey Earth Explorer site (http://earthexplorer.usgs.gov/) for 151 both cities. For Kyiv, four scenes were used with the following 152 dates (April 16, 2013; May 2, 2013; June 6, 2014; October 28, 153 2014) whereas for Lviv, five were used (May 24, 2014; June 9, 154 2014; March 8, 2015; March 24, 2015; April 9, 2015). These 155 scenes had cloud cover of less than $4 \%$. Although a fifth scene 156 was downloaded for Kyiv, it resulted in linear artifacts in the 157 LCZ map and was, therefore, omitted. Multiple scenes were 158 downloaded because multitemporal information improves the LCZ classification as found by [12].

The algorithm to create the LCZ classification requires training data. These data should cover homogeneous areas that are as large as possible or at least the minimum size of an LCZ, i.e., around $1 \mathrm{~km}^{2}$. Fig. 2 shows the training areas, whereas Table II contains details of these training areas, in particular the number of polygons digitized per LCZ and the area covered by the training areas in each city. In some cases, the number of polygons is small since the actual proportion of some LCZs in each city is small. A random stratified sample of 1125 pixels at the original resolution of $120 \mathrm{~m}$ was selected from the city of Kyiv This was used for independent validation of the LCZ map of Kyiv.

To then undertake an independent comparison, two different datasets were used. The first is the GlobeLand30 land cover dataset at a resolution of $30 \mathrm{~m}$ that was recently developed by the National Geomatics Center of China [21] for 2010. This land cover dataset is freely available for downloading and contains nine classes including one for artificial surfaces. This latter class covers urban areas, roads, rural cottages, and mines. They used a supervised approach to first classify artificial surfaces followed by the application of a segmentation method. Artificial surfaces were then classified based on exceedance of a minimum threshold of $50 \%$ within the identified objects. Finally, manual verification was undertaken using high-resolution imagery from Google Earth. The user's accuracy was estimated at around $87 \%$ for this class, whereas the overall accuracy for all classes in this global product is around $80 \%$ [17]. 33 .

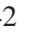

\section{(1)}

\section{(10)} , 


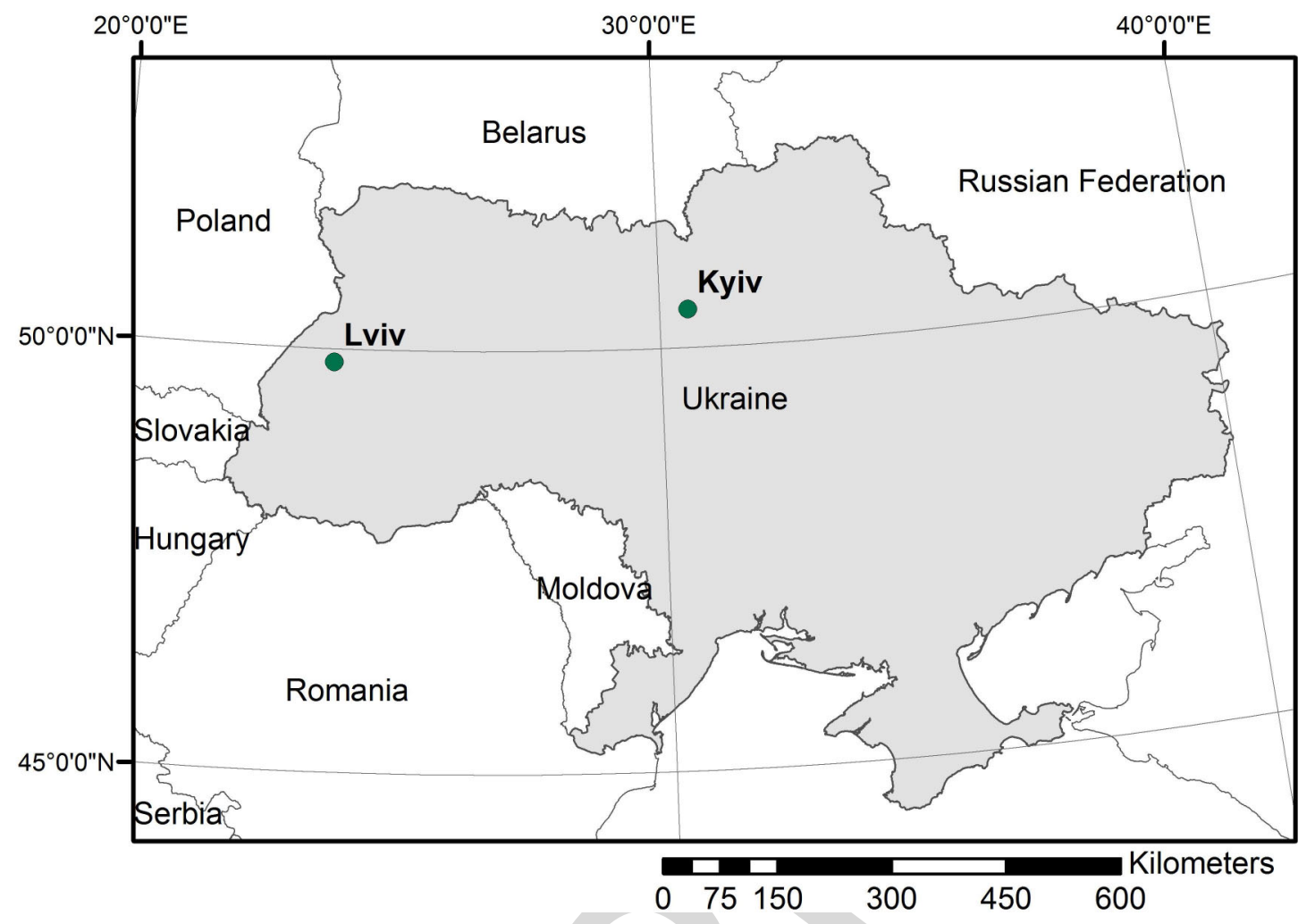

F1:1 Fig. 1. Location of the cities of Kyiv and Lviv in Ukraine.

The second dataset for independent comparison is from OSM. OSM is a community-based mapping initiative in which volunteers map features such as buildings, roads, land use, and points of interest [22]. The data are openly available through an open database commons open data license and were downloaded from the GeoFabrik website in Germany (http://www.geofabrik.de). The features are organized as polygons, lines, and points. Only the point shapefile was used in this study in which points of interest of type cities, villages, and towns were extracted. These point locations are meant to correspond to the center of these features and will be used as an additional source of independent comparison with the LCZ classification of Kyiv and Lviv. Work is ongoing to investigate how OSM line and polygon features can be used in both LCZ classification and validation in the future.

\section{B. Methodology for LCZ Classification}

The workflow in [12] was employed to create the LCZ maps for Kyiv and Lviv. A modified version of this workflow is shown in Fig. 3. The Landsat 8 imagery was downloaded and the training areas were created for each city as outlined in Section III-A. The Landsat 8 imagery was then classified using a random forest classifier. Instead of using the SAGA software [23] from [12], the workflow was processed using R. Each Landsat 8 scene contains 11 bands, 8 of which are multispectral (at a resolution of $30 \mathrm{~m}$ ), 1 is panchromatic (at $15 \mathrm{~m}$ resolution), and 2 are thermal (acquired at $100 \mathrm{~m}$ resolution, but delivered resampled to $30 \mathrm{~m}$ ). Despite possible redundancy, all bands were used in the classification since random forest is relatively insensitive toward the number of features. All bands from the 216 five scenes were resampled using the area mean to a common 217 resolution of $120 \mathrm{~m}$, which is within the range of 100-150 m 218 recommended by [12]. Therefore, 48 inputs were provided to 219 the random forest classifier for Kyiv (to include all four scenes) 220 and 60 inputs were used in total for Lviv. Experimentation with 221 the number of trees in the random forest classifier revealed a 222 flattening out of the out of bag error curve at 128 trees (see 223 Table III) so this was used as the final configuration to create 224 the LCZ classifications of the two cities. Each tree in the clas- 225 sifier is constructed using a sample in which around one third 226 of the observations are left out. Once all trees are constructed, 227 the resulting class for a given set of inputs is based on majority 228 voting. The out of bag error is the prediction error based on the 229 trees that did not use a specific sample for training. 230

The LCZ map was then examined using Google Earth to look 231 for any poorly classified areas. Based on this qualitative inspec- 232 tion, additional training areas were added and the classification 233 was rerun. Using the advice provided in [11], the minimum 234 number of training areas per class suggested was 4-5 (where 235 it was possible to identify this number). Thus, areas with larger 236 number of training areas (Table II) reflect attempts to improve 237 the classification and represent additional training areas. This 238 step is repeated as many times as necessary.

An additional experiment was undertaken in which the mini- 240 mum, mean, and maximum value of the resampled $120 \mathrm{~m}$ bands 241 were provided to the classifier, increasing the number of inputs 242 (or features) from 48 to 144 for Kyiv and from 60 to 180 for 243 Lviv. The idea was to determine whether providing additional 244 information about the spectral variation to the classifier, which 245 

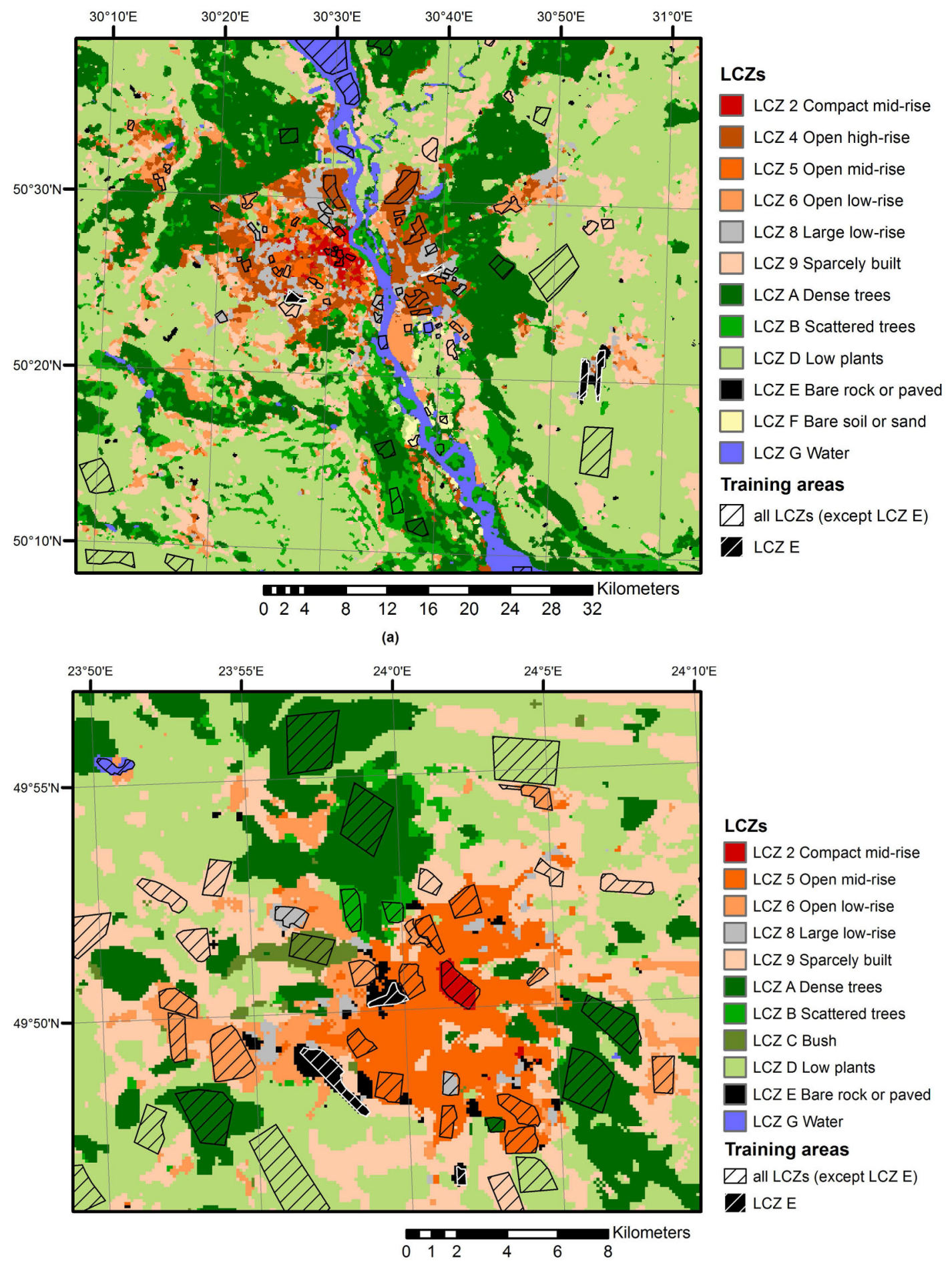

(b)

F2:1 Fig. 2. Training areas in (a) Kyiv and (b) Lviv plotted on the LCZ maps.

would otherwise be lost in the resampling, might help to better discriminate between different LCZs.

Two new steps were then added to the workflow of [12]. The first was to undertake an independent validation using a random stratified sample (Fig. 3 item 1) as described in the section on data inputs. Such an approach has not yet been tried for validation of LCZ maps.
A postclassification filter of a two pixel window was then 253 applied to the image to create more homogeneous LCZs. This 254 is because LCZs are meant to be areas of around $1 \mathrm{~km}^{2}$ since 255 they must be large enough to have an effect on the local climate. 256

The second additional step to the workflow (Fig. 3 item 2) 257 was to compare the map with other sources of independent 258 data to determine the agreement. The GlobeLand30 land cover 259 


\begin{tabular}{|l|c|c|c|c|}
\hline \multirow{2}{*}{ LCZ } & \multicolumn{2}{|c|}{$\begin{array}{c}\text { Number of training } \\
\text { areas }\end{array}$} & \multicolumn{2}{c|}{ Area $\left(\mathrm{km}^{2}\right)$} \\
\cline { 2 - 5 } & Kyiv & Lviv & Kyiv & Lviv \\
\hline LCZ 2 Compact mid-rise & 3 & 1 & 2.98 & 1.57 \\
\hline LCZ 4 Open high-rise & 6 & N/A & 17.73 & N/A \\
\hline LCZ 5 Open mid-rise & 7 & 7 & 3.70 & 7.65 \\
\hline LCZ 6 Open low-rise & 12 & 8 & 9.04 & 8.50 \\
\hline LCZ 8 Large low-rise & 16 & 2 & 9.66 & 1.43 \\
\hline LCZ 9 Sparsely built & 7 & 9 & 10.50 & 10.50 \\
\hline LCZ A Dense trees & 7 & 6 & 17.02 & 17.37 \\
\hline LCZ B Scattered trees & 2 & 2 & 3.40 & 1.53 \\
\hline LCZ C Bush, scrub & N/A & 1 & N/A & 1.56 \\
\hline LCZ D Low plants & 6 & 5 & 53.16 & 15.11 \\
\hline LCZ E Bare rock or paved & 6 & 3 & 8.41 & 2.46 \\
\hline LCZ F Bare soil or sand & 4 & N/A & 1.43 & N/A \\
\hline LCZ G Water & 6 & 1 & 31.05 & 0.53 \\
\hline
\end{tabular}

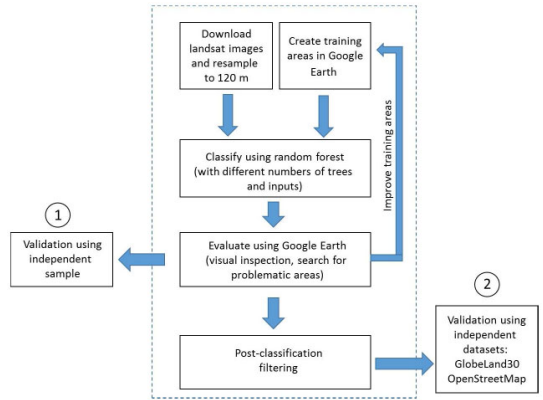

TABLE II

TRAINING AREAS FOR KYIV AND LVIV
Fig. 4 shows the LCZ map of Kyiv, which contains 12 out of the 17 LCZ types. The only compact LCZ is 2 (compact mid-rise) as there are no examples of LCZs 1 and 3 in Kyiv.

\section{RESUlts}

\section{A. LCZ Classifications of Kyiv and Lviv}

LCZ 7 (lightweight low-rise) and LCZ 10 (heavy industry) are 276 also not found in Kyiv. The Dnipro River clearly cuts the city in 277 half with most of the urban types concentrated in a core around 278 the river. The business district can clearly be seen on the west- 279 ern bank of the river. The whole western part of the city looks 280 very heterogeneous, without a clear sense of structure. This is 281 also seen very clearly when the city is viewed using Google 282 Earth imagery, which is not shown here due to the size of the 283 area. However, both cities can be viewed via the WUDAPT 284 website (http://www.wudapt.org), which includes Google Earth 285 imagery. This heterogeneity contrasts very sharply with much 286 more organized cities such as those in North America and other 287 parts of Europe. On the eastern side and to the north of the city 288 is LCZ 4 (Open high-rise), which is characterized by large areas 289 of newer residential buildings (i.e., post-1965 and also some 290 post-1987). This part of the city looks more organized and may 291 reflect more recent planning compared to the much older his- 292 torical center. Areas of light industry are scattered throughout 293 the city (LCZ 8-large low-rise). Around Kyiv is a consider- 294 able amount of greenspace (LCZs A, B, and D) with sparsely 295 built settlements (LCZ 9) appearing as small clusters as one 296 moves away from the center of the city. This leap frog devel- 297 opment reflects urban satellite developments for a commuting 298 population.

The LCZ classification of Lviv is given in Fig. 5. Like 300 Kyiv, it has the same urban LCZ types although LCZ 4301 (open high-rise) is absent. However, apart from a small cen- 302 tral patch of LCZ 2 (compact mid-rise), the majority of 303 the center is a large homogenous area of LCZ 5 (open 304 low-rise). Examining photographs from Google street view 305 reveals building architecture that is similar to the older residen- 306 tial part of the city of Vienna, reflecting the Austro-Hungarian 307 history. The city's urban structure is more organized, which is 308 in sharp contrast to the much more heterogeneous mix of LCZs 309 seen in Kyiv. Areas of sparsely built settlements (LCZ 9) are 310 also much larger and closer to the city center. 311

Table IV provides a comparison of the size of the LCZs in 312 Kyiv and Lviv after official city boundaries were used to clip 313 the LCZ maps. In absolute terms Kyiv is clearly much bigger, 314 but when compared relatively, Lviv has more than $60 \%$ of urban 315 LCZs compared to Kyiv, which has just under 40\%. While Kyiv 316 has almost 15\% of its area covered by LCZ 4 (open high-rise), 317 which is absent in Lviv, LCZ 5 (open mid-rise) is much more 318 prevalent in Lviv than Kyiv. Lviv has a higher amount of LCZ 9319 (sparsely built), which may reflect agricultural areas surround- 320 ing the city, whereas there are considerably more forested areas 321 around the city of Kyiv. Water is also higher in Kyiv, reflecting 322 the river that runs through the city. 323

The confusion matrix for the training data for Kyiv is 324 shown in Table V, where the out of bag error was 3.82\%. 325 Table VI shows the results when using the additional inputs 326 from the minimum and maximum values of the bands in addi- 327 tion to the mean. The out of bag error improves marginally to 328 $3.5 \%$. The overall accuracy is $96 \%$, increasing slightly with 329 the additional inputs to $97 \%$. The natural classes are all cap- 330 tured extremely well with good results for the urban classes. 331 However, there is some confusion between the compact and 332 open urban classes. When considering all the inputs (Table VI), 333 


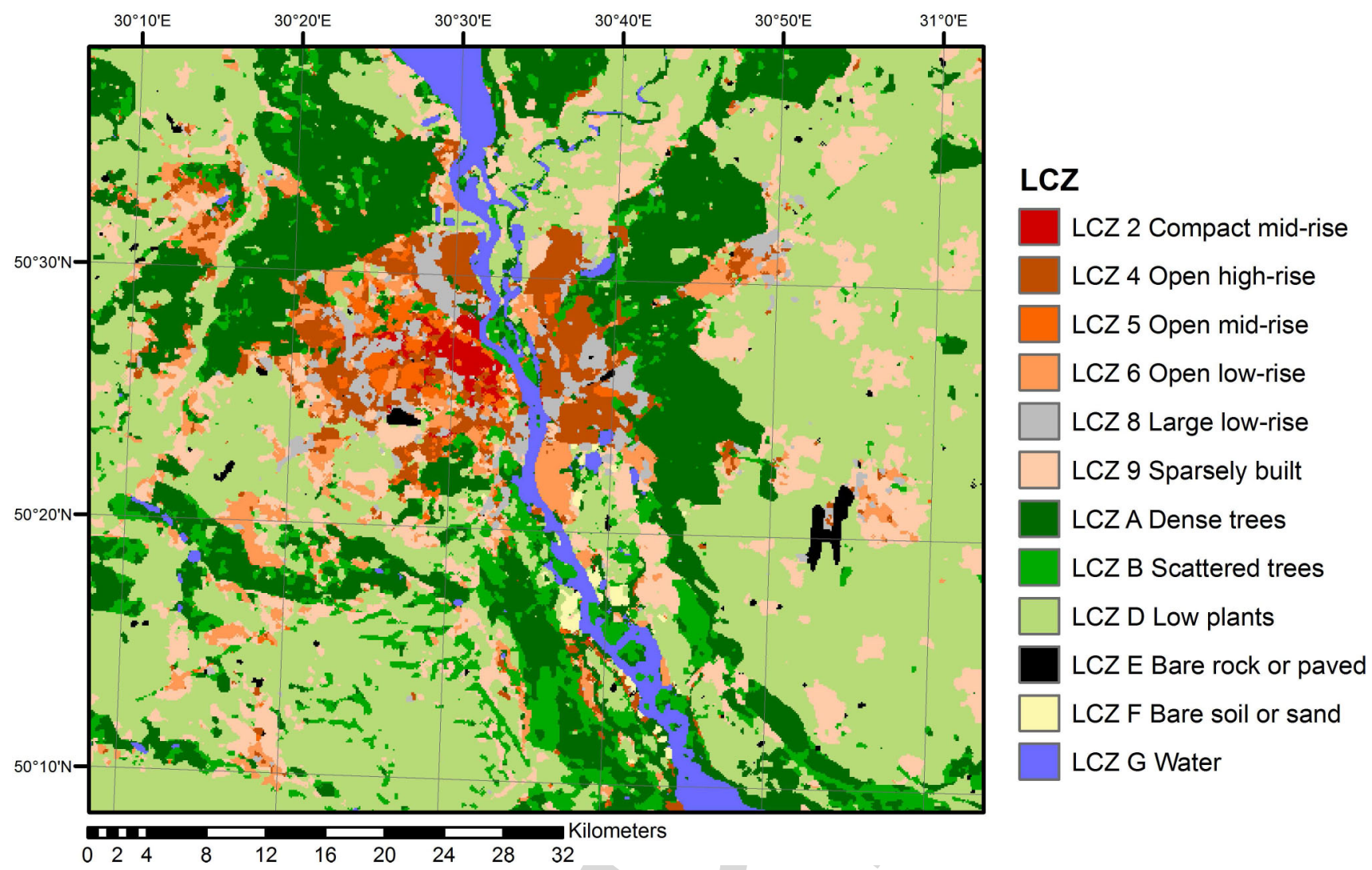

F4:1 Fig. 4. LCZ map of Kyiv.

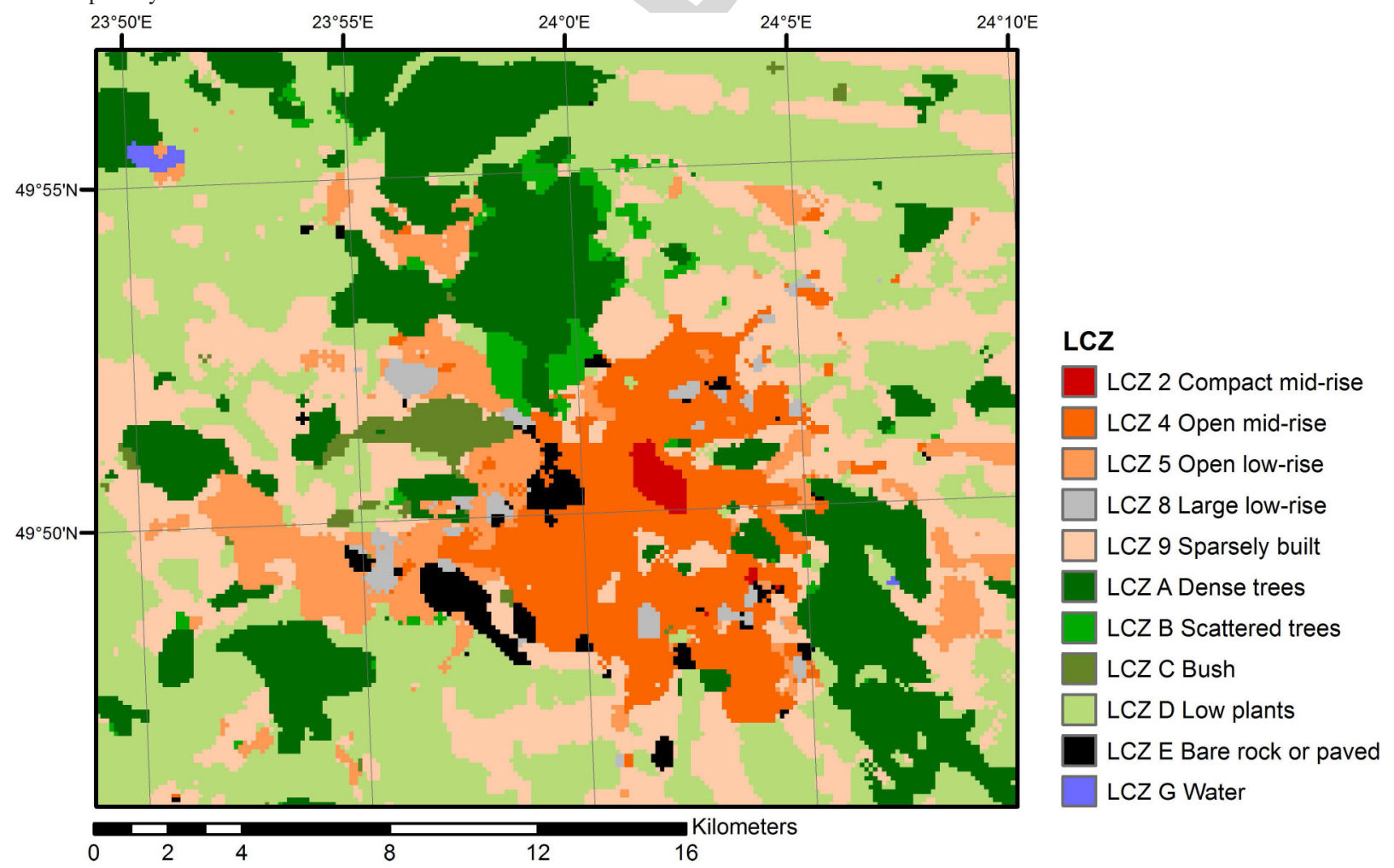

F5:1 Fig. 5. LCZ map of Lviv.

334 LCZs 4, 5, and 6 decrease in accuracy slightly but there is 335 less confusion between LCZs 4 and 8. There are other small 336 tradeoffs that can be observed when comparing Tables V 337 and VI. However, there appears to be very small differences between the results with and without the additional inputs. The 338 results for Lviv are similar to Kyiv. The out of bag error is 339 slightly larger at $7 \%$ but the confusion matrix shows similar 340 patterns. 
TABLE IV

AREAS OF LCZS FOR KYIV AND LVIV CONTAINED WITHIN THE OFFICIAL CITY BOUNDARIES

\begin{tabular}{|l|c|c|c|c|}
\hline \multirow{2}{*}{ LCZ } & \multicolumn{2}{|c|}{ Area $\left(\mathrm{km}^{2}\right)$} & \multicolumn{2}{c|}{ Area (\%) } \\
\cline { 2 - 5 } & Kyiv & Lviv & Kyiv & Lviv \\
\hline LCZ 2 Compact mid-rise & 18.32 & 2.03 & 2.22 & 1.34 \\
\hline LCZ 4 Open high-rise & 117.66 & N/A & 14.28 & N/A \\
\hline LCZ 5 Open mid-rise & 35.64 & 48.20 & 4.32 & 31.82 \\
\hline LCZ 6 Open low-rise & 48.56 & 13.55 & 5.89 & 8.95 \\
\hline LCZ 8 Large low-rise & 66.61 & 5.43 & 8.08 & 3.58 \\
\hline LCZ 9 Sparsely built & 34.52 & 25.40 & 4.19 & 16.77 \\
\hline LCZ A Dense trees & 332.81 & 32.47 & 40.38 & 21.44 \\
\hline LCZ B Scattered trees & 71.74 & 4.18 & 8.70 & 2.76 \\
\hline LCZ C Bush, scrub & N/A & 5.00 & N/A & 3.30 \\
\hline LCZ D Low plants & 52.26 & 8.15 & 6.34 & 5.38 \\
\hline LCZ E Bare rock or paved & 3.33 & 7.06 & 0.40 & 4.66 \\
\hline LCZ F Bare soil or sand & 3.01 & N/A & 0.37 & N/A \\
\hline LCZ G Water & 39.73 & N/A & 4.82 & N/A \\
\hline
\end{tabular}

\section{B. Validation With Sample Data}

The sample validation dataset described in Section III-A was used to assess the accuracy of the LCZ maps. Tables VII and VIII provide confusion matrices for Kyiv for the two different input datasets. Table VII contains results for the random forest classified with only the resampled mean of the bands as inputs while Table VIII shows the results when the minimum, mean, and maximum are included. The overall accuracy using the mean as inputs is $64 \%$, where the poorest class is LCZ 4 (open high-rise). There is some confusion between LCZ 4 and other urban classes and LCZ E (bare rock or paved), and there are issues with LCZ 5 (open mid-rise), which is also mistaken for other classes. The overall accuracy improves slightly to $66 \%$ when including more inputs, where the user accuracy of some urban classes improves but the tradeoff is a slight decrease in the producer's accuracy. Although the effects of adding additional inputs is more pronounced on the independent validation dataset compared to the training data, it appears that there is little to be gained from adding these extra inputs to the classifier. Kyiv is very heterogeneous, particularly in the western part of the city, which may partly explain these accuracy figures. Further training data may be needed to improve the classification.

\section{Comparison With GlobeLand30}

Figs. 6 and 7 show the GlobeLand30 land cover map superimposed on the LCZ maps of Kyiv and Lviv, respectively. For Kyiv, the artificial surfaces appear to match the urban types extremely well from a visual point of view, including LCZ 9 (sparsely built) that covers scattered settlements around Kyiv. Large, homogeneous patches of forest cover and water are also captured well as are grassland and cultivated areas (corresponding to LCZ D low plants). However, there are some exceptions, e.g., Fig. 8(a) shows an area on high-resolution imagery from Google Earth where GlobeLand30 classifies the area as Forest and the area is LCZ D (low plants). The image contains a flood plain, which becomes inundated during flooding and is, therefore, left in a natural state. Thus, the LCZ map better captures this area than the GlobeLand 30 product.

This overall correspondence is confirmed in Table IX, which contains a confusion matrix comparing the LCZ classification with the GlobeLand30 land cover product. The LCZs were first 382 mapped onto the GlobeLand30 classes as follows. 383

1) Urban LCZs and LCZ E (since this latter one is an OR 384 class of bare rock or paved) map onto artificial surfaces. 385

2) LCZs A and B map onto the Forest class. 386

3) LCZ C maps onto shrubland. 387

4) LCZ D maps onto cultivated land and grassland which 388 were collapsed into a single class in the confusion 389 matrix.

5) LCZ F maps onto bare soil or sand. 391

6) LCZ G maps onto water bodies. 392

There is no wetland class in the LCZ classification, and 393 classes that are related to the tundra and snow were omitted. 394 LCZ9 (sparsely built) could be either artificial surfaces, grass- 395 land or cultivated land. For the purpose of calculating corre- 396 spondence between the two datasets, LCZ9 is mapped onto the 397 GlobeLand30 class artificial surfaces. 398

Table IX shows that the overall correspondence between the 399 two datasets was $83 \%$ for Kyiv. The user's and producer's accu- 400 racies were generally high except for classes that were simply 401 not present (e.g., shrubland) or where there is no corresponding 402 class (e.g., wetland).

For Lviv (Fig. 7), the visual comparison shows similar corre- 404 spondence between the artificial surfaces class of GlobeLand30 405 and the urban types, with the exception of LCZ 9 (sparsely 406 built), which often corresponds to the cultivated land class of 407 GlobeLand30. This is not surprising as this class contains less 408 than 20\% artificial surfaces but still is considered an urban 409 type in the LCZ classification. Correspondence with forests is 410 also reasonably good although there are exceptions. For exam- 411 ple, Fig. 8(b) shows an area on high-resolution imagery from 412 Google Earth where GlobeLand30 classifies the area as arti- 413 ficial surfaces while the LCZ classification indicates LCZ B 414 (scattered trees). The image clearly shows scattered houses but 415 not an artificial surface fraction of greater than 50\%. Although 416 there are scattered trees, this could also be an example of LCZ 417 9 (sparsely built), in which case both maps would be wrong. 418 Moreover, one large area of LCZ C (bush, scrub) has been clas- 419 sified as cultivated land in the GlobeLand30 product. However, 420 it was difficult to tell from Google, Earth which one is actually 421 correct. Thus, Google street view photographs were examined 422 in this area and they revealed the presence of shrubs. 423

Table X contains the correspondence between the two prod- 424 ucts, which shows the overall agreement is at $75 \%$ and thus 425 somewhat lower than for Kyiv. Table X shows that there is 426 some confusion between water bodies, forest, and cultivated 427 areas/grassland, whereas the highest agreement is for the urban 428 LCZs.

\section{Comparison With OSM}

Figs. 9 and 10 show the city, towns, and villages from OSM 431 overlaid on top of the LCZ maps of Kyiv and Lviv, respec- 432 tively. A visual inspection shows that the OSM feature called 433 city (which is single point of interest) falls in LCZ 2, which is to 434 be expected as this is the business center of each city. The towns 435 and villages also generally fall in urban classes as expected. 436 Table XI summarizes the correspondence between the LCZs 437 
T5:1
TABLE V

CONFUSION MATRIX FOR KYIV USING THE MEAN AS INPUTS

\begin{tabular}{|c|c|c|c|c|c|c|c|c|c|c|c|c|c|c|}
\hline LCZ & 2 & 4 & 5 & 6 & 8 & 9 & $\mathrm{~A}$ & $\mathrm{~B}$ & $\mathrm{D}$ & $\mathrm{E}$ & $\mathrm{F}$ & $\mathrm{G}$ & Sum & UA \\
\hline 2 & 231 & 40 & 10 & 4 & 21 & 0 & 0 & 0 & 0 & 0 & 0 & 0 & 306 & 0.75 \\
\hline 4 & 11 & 1842 & 16 & 10 & 82 & 4 & 0 & 0 & 0 & 2 & 0 & 0 & 1967 & 0.94 \\
\hline 5 & 13 & 106 & 218 & 25 & 4 & 6 & 0 & 1 & 0 & 0 & 0 & 0 & 373 & 0.58 \\
\hline 6 & 3 & 24 & 3 & 894 & 3 & 23 & 0 & 0 & 1 & 0 & 0 & 0 & 951 & 0.94 \\
\hline 8 & 2 & 142 & 1 & 6 & 799 & 0 & 0 & 1 & 1 & 8 & 1 & 0 & 961 & 0.83 \\
\hline 9 & 1 & 4 & 0 & 31 & 0 & 1072 & 0 & 0 & 30 & 0 & 0 & 0 & 1138 & 0.94 \\
\hline A & 0 & 0 & 0 & 0 & 0 & 1 & 1885 & 2 & 2 & 0 & 0 & 0 & 1890 & 1.00 \\
\hline B & 0 & 0 & 0 & 0 & 0 & 0 & 6 & 371 & 5 & 0 & 0 & 0 & 382 & 0.97 \\
\hline D & 0 & 1 & 0 & 0 & 0 & 13 & 0 & 1 & 5804 & 1 & 0 & 0 & 5820 & 1.00 \\
\hline E & 0 & 4 & 0 & 0 & 9 & 4 & 0 & 0 & 14 & 908 & 0 & 0 & 939 & 0.97 \\
\hline F & 0 & 0 & 0 & 0 & 2 & 0 & 0 & 0 & 1 & 0 & 143 & 0 & 146 & 0.98 \\
\hline G & 0 & 0 & 0 & 0 & 0 & 0 & 0 & 0 & 0 & 0 & 0 & 3590 & 3590 & 1.00 \\
\hline Sum & 261 & 2163 & 248 & 970 & 920 & 1123 & 1891 & 376 & 5858 & 919 & 144 & 3590 & & \\
\hline PA & 0.89 & 0.85 & 0.88 & 0.92 & 0.87 & 0.95 & 1.00 & 0.99 & 0.99 & 0.99 & 0.99 & 1.00 & OA & 0.96 \\
\hline
\end{tabular}

Columns contain the training data while rows contain the results from the LCZ map.

TABLE VI

Confusion Matrix for KYIV Using the Minimum, Mean, and Maximum as Inputs

\begin{tabular}{|c|c|c|c|c|c|c|c|c|c|c|c|c|c|c|}
\hline LCZ & 2 & 4 & 5 & 6 & 8 & 9 & $\mathrm{~A}$ & $\mathrm{~B}$ & $\mathrm{D}$ & $\mathrm{E}$ & $\mathrm{F}$ & $\mathrm{G}$ & Sum & UA \\
\hline 2 & 239 & 36 & 7 & 4 & 20 & 0 & 0 & 0 & 0 & 0 & 0 & 0 & 306 & 0.78 \\
\hline 4 & 11 & 1833 & 18 & 10 & 88 & 5 & 0 & 0 & 0 & 2 & 0 & 0 & 1967 & 0.93 \\
\hline 5 & 13 & 114 & 210 & 22 & 7 & 7 & 0 & 0 & 0 & 0 & 0 & 0 & 373 & 0.56 \\
\hline 6 & 4 & 17 & 11 & 890 & 5 & 24 & 0 & 0 & 0 & 0 & 0 & 0 & 951 & 0.94 \\
\hline 8 & 8 & 86 & 4 & 6 & 850 & 1 & 0 & 0 & 0 & 4 & 2 & 0 & 961 & 0.88 \\
\hline 9 & 0 & 6 & 2 & 21 & 0 & 1080 & 0 & 0 & 29 & 0 & 0 & 0 & 1138 & 0.95 \\
\hline A & 0 & 0 & 0 & 0 & 0 & 0 & 1886 & 1 & 3 & 0 & 0 & 0 & 1890 & 1.00 \\
\hline B & 0 & 0 & 0 & 0 & 0 & 0 & 6 & 372 & 4 & 0 & 0 & 0 & 382 & 0.97 \\
\hline D & 0 & 0 & 0 & 0 & 0 & 4 & 0 & 0 & 5816 & 0 & 0 & 0 & 5820 & 1.00 \\
\hline E & 0 & 1 & 0 & 0 & 11 & 3 & 0 & 0 & 16 & 908 & 0 & 0 & 939 & 0.97 \\
\hline F & 0 & 1 & 0 & 0 & 1 & 0 & 0 & 0 & 0 & 1 & 143 & 0 & 146 & 0.98 \\
\hline G & 0 & 0 & 0 & 0 & 0 & 0 & 0 & 0 & 0 & 0 & 0 & 3590 & 3590 & 1.00 \\
\hline Sum & 275 & 2094 & 252 & 953 & 982 & 1124 & 1892 & 373 & 5868 & 915 & 145 & 3590 & & \\
\hline PA & 0.87 & 0.88 & 0.83 & 0.93 & 0.87 & 0.96 & 1.00 & 1.00 & 0.99 & 0.99 & 0.99 & 1.00 & OA & 0.97 \\
\hline
\end{tabular}

Columns contain the training data while rows contain the results from the LCZ map.

TABLE VII

Confusion Matrix for KYIV USing the SAmple VALidation Dataset and the Mean as Inputs

\begin{tabular}{|c|c|c|c|c|c|c|c|c|c|c|c|c|c|c|}
\hline LCZ & 2 & 4 & 5 & 6 & 8 & 9 & A & B & D & E & F & G & Sum & UA \\
\hline 2 & $\mathbf{3 4}$ & 15 & 1 & 3 & 3 & 0 & 0 & 0 & 0 & 0 & 0 & 1 & 57 & 0.60 \\
\hline 4 & 7 & $\mathbf{3 7}$ & 6 & 0 & 6 & 1 & 0 & 0 & 0 & 0 & 0 & 0 & 57 & 0.65 \\
\hline 5 & 5 & 29 & $\mathbf{2 0}$ & 13 & 3 & 2 & 2 & 0 & 0 & 0 & 0 & 0 & 74 & 0.27 \\
\hline 6 & 0 & 9 & 1 & $\mathbf{4 4}$ & 1 & 14 & 0 & 1 & 0 & 0 & 0 & 0 & 70 & 0.63 \\
\hline 8 & 6 & 39 & 2 & 5 & $\mathbf{7 0}$ & 6 & 1 & 0 & 1 & 5 & 2 & 0 & 137 & 0.51 \\
\hline 9 & 0 & 4 & 0 & 13 & 1 & $\mathbf{5 6}$ & 0 & 1 & 15 & 0 & 0 & 0 & 90 & 0.62 \\
\hline A & 0 & 2 & 1 & 3 & 0 & 0 & $\mathbf{1 1 1}$ & 8 & 3 & 0 & 0 & 1 & 129 & 0.86 \\
\hline B & 0 & 3 & 4 & 3 & 1 & 7 & 35 & $\mathbf{3 1}$ & 11 & 0 & 0 & 0 & 95 & 0.33 \\
\hline D & 0 & 0 & 0 & 0 & 2 & 17 & 5 & 3 & $\mathbf{1 5 0}$ & 4 & 0 & 0 & 181 & 0.83 \\
\hline E & 1 & 10 & 1 & 0 & 7 & 2 & 0 & 1 & 4 & $\mathbf{1 1}$ & 0 & 0 & 37 & 0.30 \\
\hline F & 0 & 2 & 0 & 0 & 2 & 2 & 1 & 0 & 24 & 3 & $\mathbf{5 8}$ & 0 & 92 & 0.63 \\
\hline G & 1 & 1 & 0 & 1 & 0 & 0 & 6 & 0 & 2 & 0 & 0 & $\mathbf{9 5}$ & 106 & 0.90 \\
\hline Sum & 54 & 151 & 36 & 85 & 96 & 107 & 161 & 45 & 210 & 23 & 60 & 97 & 1125 & \\
\hline PA & 0.63 & 0.25 & 0.56 & 0.52 & 0.73 & 0.52 & 0.69 & 0.69 & 0.71 & 0.48 & 0.97 & 0.98 & OA & 0.64 \\
\hline
\end{tabular}

Columns contain the validation data while rows contain the results from the LCZ map. 
T8:1

TABLE VIII

Confusion Matrix for KYiV USing the Sample Validation DataSet Using the Minimum, Mean, and Maximum as inputs

\begin{tabular}{|c|c|c|c|c|c|c|c|c|c|c|c|c|c|c|}
\hline LCZ & 2 & 4 & 5 & 6 & 8 & 9 & A & B & D & E & F & G & Sum & UA \\
\hline 2 & $\mathbf{4 0}$ & 14 & 0 & 0 & 2 & 0 & 0 & 0 & 0 & 0 & 0 & 1 & 57 & 0.70 \\
\hline 4 & 4 & $\mathbf{4 3}$ & 4 & 0 & 5 & 1 & 0 & 0 & 0 & 0 & 0 & 0 & 57 & 0.75 \\
\hline 5 & 4 & 31 & $\mathbf{2 3}$ & 7 & 4 & 3 & 2 & 0 & 0 & 0 & 0 & 0 & 74 & 0.31 \\
\hline 6 & 0 & 8 & 2 & $\mathbf{4 6}$ & 1 & 11 & 0 & 1 & 0 & 1 & 0 & 0 & 70 & 0.66 \\
\hline 8 & 9 & 30 & 1 & 5 & $\mathbf{7 8}$ & 5 & 0 & 0 & 3 & 4 & 2 & 0 & 137 & 0.57 \\
\hline 9 & 0 & 4 & 1 & 9 & 2 & $\mathbf{5 6}$ & 0 & 1 & 17 & 0 & 0 & 0 & 90 & 0.62 \\
\hline A & 0 & 4 & 1 & 0 & 0 & 0 & $\mathbf{1 1 2}$ & 7 & 4 & 0 & 0 & 1 & 129 & 0.87 \\
\hline B & 0 & 3 & 5 & 2 & 1 & 7 & 33 & $\mathbf{3 3}$ & 11 & 0 & 0 & 0 & 95 & 0.35 \\
\hline D & 0 & 0 & 0 & 1 & 1 & 19 & 4 & 2 & $\mathbf{1 4 6}$ & 7 & 0 & 1 & 181 & 0.81 \\
\hline E & 1 & 8 & 1 & 0 & 8 & 2 & 0 & 1 & 4 & $\mathbf{1 2}$ & 0 & 0 & 37 & 0.32 \\
\hline F & 0 & 0 & 0 & 0 & 3 & 5 & 1 & 0 & 22 & 0 & $\mathbf{6 1}$ & 0 & 92 & 0.66 \\
\hline G & 1 & 0 & 1 & 1 & 0 & 0 & 2 & 1 & 1 & 0 & 1 & $\mathbf{9 8}$ & 106 & 0.92 \\
\hline Sum & 59 & 145 & 39 & 71 & 105 & 109 & 154 & 46 & 208 & 24 & 64 & 101 & $\mathbf{1 1 2 5}$ & \\
\hline PA & 0.68 & 0.30 & 0.59 & 0.65 & 0.74 & 0.51 & 0.73 & 0.72 & 0.70 & 0.50 & 0.95 & 0.97 & OA & 0.66 \\
\hline
\end{tabular}

Columns contain the validation data while rows contain the results from the LCZ map.

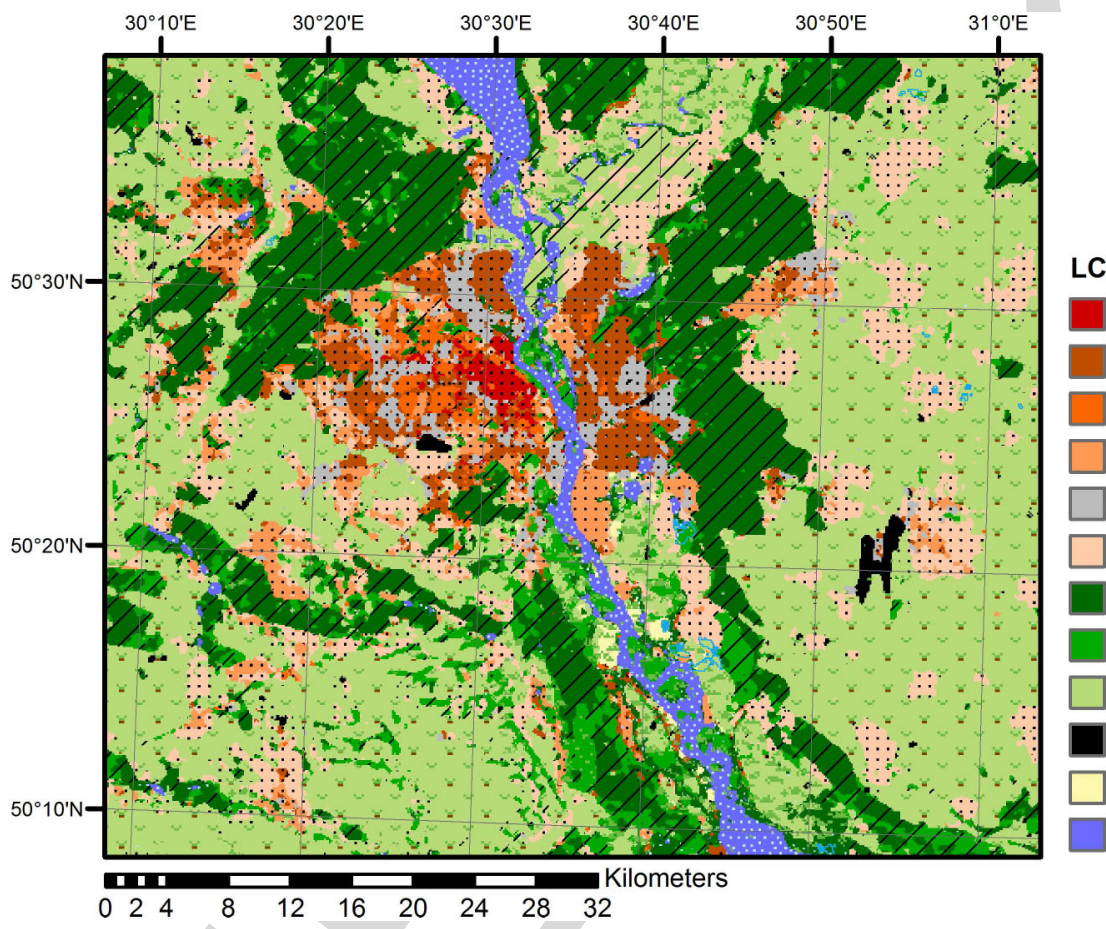

LCZ

LCZ 2 Compact mid-rise

LCZ 4 Open high-rise

LCZ 5 Open mid-rise

LCZ 6 Open low-rise

LCZ 8 Large low-rise

LCZ 9 Sparsely built

LCZ A Dense trees

LCZ B Scattered trees

LCZ D Low plants

LCZ E Bare rock or paved

LCZ F Bare soil or sand

LCZ G Water

Fig. 6. LCZ map of Kyiv compared with the GlobeLand30 land cover product.

and the city, towns, and villages. In the case of Kyiv, all towns fall in urban classes or LCZ E (bare rock or paved), whereas one town in Lviv falls in LCZ A (dense trees), indicating a misclassification. For villages in Kyiv, 6 out of 136 locations fall in nonurban classes (roughly $4 \%$ ) while all villages in Lviv fall in urban classes or LCZ E (bare rock or paved). Thus, the results show a good correspondence between the points of interest for the city, towns, and villages and the LCZ classification.

\section{DISCUSSION}

The LCZ methodology is simple to implement using freely available satellite imagery and software, as per the original goal of WUDAPT [12]. The results also illustrate that the 449 LCZ classification provides a standardized way of mapping 450 and comparing cities. Although Kyiv and Lviv have similar- 451 ities due to their geographical proximity, they are also quite 452 different cities in terms of size, topography, and urban form. 453 The LCZ classification provides a way of clearly visualizing 454 and quantifying these differences in a standardized, transfer- 455 able manner. However, there are challenges in working with 456 small cities such as Lviv. For example, finding sufficient train- 457 ing areas of a large enough size was much more difficult for 458 Lviv than Kyiv.

Since the random forest classifier provides an out of bag 460 error, there is theoretically no need for an additional test dataset. 461 



Fig. 7. LCZ map of Lviv compared with the GlobeLand30 land cover product.

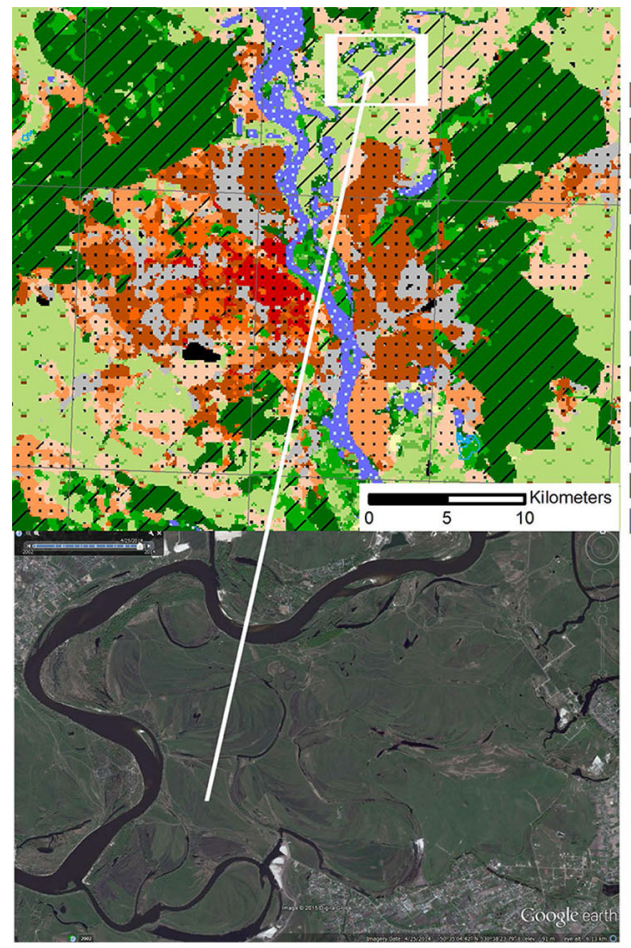

(a)

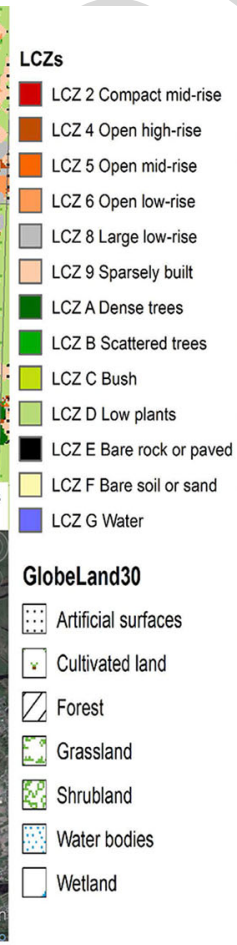

LCZ2 2 Compact mid-rise LCZ 5 Open mid-rise LCZ 6 Open low-rise
LCZ 8 Large low-rise $\square$ LCZ 9 Sparsely buil

$\square$ LCZC Bush

LCZE Bare rock or paved LCZ F Bare soil or sand GlobeLand30 :-: Artificial surfaces Cultivated land D/ Forest E. Grassland Shrubland Water bodies



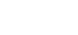

\section{GlobeLand30}

::: Artificial surfaces

Cultivated land

$\triangle$ Forest

Water bodies

F8:1 Fig. 8. Examples of disagreeing areas between the LCZ map and GlobeLand30 in (a) Kyiv and (b) Lviv with Google Earth imagery for comparison.

However, validation was undertaken in this study using an independent test dataset to provide additional confidence in the classification. The results, applied only to Kyiv, indicated that the classification accuracy is similar to other land cover products but that there is still room for improvement. However, independent validation using pixels of $120 \mathrm{~m}$ is clearly problematic since LCZs are meant to be homogenous areas of $1 \mathrm{~km}^{2}$ or larger and a postclassification filter is applied to remove 469 small occurrences of LCZ types that are not representative 470 of the larger zone. Validation using larger pixels of at least 471 $1 \mathrm{~km}^{2}$ may improve the validity of this approach and will be 472 investigated in the future.

Comparison with additional datasets did provide addi- 474 tional confidence in the LCZ classifications of both cities. 475 
T9:1

T9:2

T10:1

$\mathrm{T} 10: 2$
TABLE IX

CONFUSION MATRIX FOR KYIV COMPARING LCZS TO GLOBELAND30

\begin{tabular}{|l|c|c|c|c|c|c|c|c|c|}
\cline { 2 - 10 } \multicolumn{1}{l|}{} & \multicolumn{9}{c|}{ LCZs } \\
\hline GlobeLand30 & $\begin{array}{l}\text { Cultivated } \\
\text { land and } \\
\text { Grassland }\end{array}$ & Forest & Shrubland & Wetland & $\begin{array}{l}\text { Water } \\
\text { bodies }\end{array}$ & $\begin{array}{l}\text { Artificial } \\
\text { surfaces }\end{array}$ & Bareland & Sum & UA \\
\hline $\begin{array}{l}\text { Cultivated land and } \\
\text { Grassland }\end{array}$ & 102637 & 9595 & 0 & 0 & 575 & 5282 & 608 & 118697 & 0.86 \\
\hline Forest & 5479 & 54125 & 0 & 0 & 230 & 2198 & 5 & 62037 & 0.87 \\
\hline Shrubland & 274 & 673 & 0 & 0 & 109 & 144 & 0 & 1200 & 0.00 \\
\hline Wetland & 207 & 138 & 0 & 0 & 3 & 43 & 12 & 403 & 0.00 \\
\hline Water bodies & 465 & 2176 & 0 & 0 & 8179 & 300 & 38 & 11158 & 0.73 \\
\hline Artificial surfaces & 11497 & 3936 & 0 & 0 & 296 & 50005 & 50 & 65784 & 0.76 \\
\hline Bareland & 0 & 0 & 0 & 0 & 0 & 0 & 0 & 0 & N/A \\
\hline Sum & 120559 & 70643 & 0 & 0 & 9392 & 57972 & 713 & 259279 & 0.86 \\
\hline PA & 0.85 & 0.77 & N/A & N/A & 0.87 & 0.86 & 0.00 & OA & 0.83 \\
\hline
\end{tabular}

TABLE X

CONFUSION MATRIX FOR LVIV COMPARING LCZS TO GLOBELAND30

\begin{tabular}{|l|c|c|c|c|c|c|c|c|}
\cline { 2 - 9 } \multicolumn{1}{l|}{} & \multicolumn{9}{l|}{ LCZs } \\
\hline & $\begin{array}{l}\text { Cultivated } \\
\text { land and } \\
\text { Grassland }\end{array}$ & Forest & Shrubland & Wetland & $\begin{array}{l}\text { Water } \\
\text { bodies }\end{array}$ & $\begin{array}{l}\text { Artificial } \\
\text { surfaces }\end{array}$ & Sum & UA \\
\hline $\begin{array}{l}\text { Cultivated land and } \\
\text { Grassland }\end{array}$ & 11171 & 605 & 375 & 0 & 27 & 5053 & 17231 & 0.65 \\
\hline Forest & 702 & 6142 & 36 & 0 & 12 & 967 & 7859 & 0.78 \\
\hline Shrubland & 0 & 0 & 0 & 0 & 0 & 0 & 0 & N/A \\
\hline Wetland & 1 & 0 & 0 & 0 & 0 & 10 & 11 & 0.00 \\
\hline Water bodies & 7 & 16 & 0 & 0 & 21 & 7 & 51 & 0.41 \\
\hline Artificial surfaces & 666 & 489 & 22 & 0 & 0 & 9236 & 10413 & 0.89 \\
\hline Sum & 12547 & 7252 & 433 & 0 & 60 & 15273 & 35565 & \\
\hline PA & 0.89 & 0.85 & N/A & N/A & 0.35 & 0.60 & OA & 0.75 \\
\hline
\end{tabular}

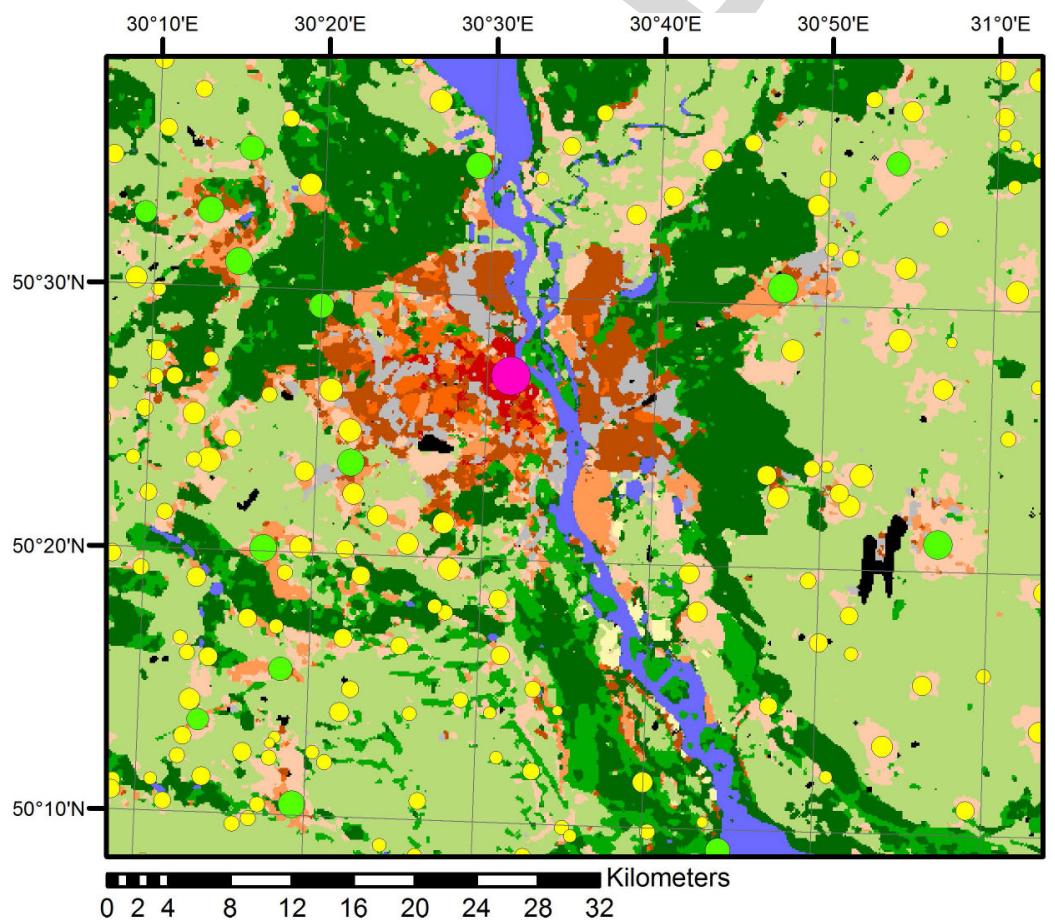

LCZ

LCZ 2 Compact mid-rise

LCZ 4 Open high-rise

LCZ 5 Open mid-rise

LCZ 6 Open low-rise

LCZ 8 Large low-rise

LCZ 9 Sparsely built

LCZ A Dense trees

LCZ B Scattered trees

$\square$ LCZ D Low plants

LCZ E Bare rock or paved

LCZ F Bare soil or sand

LCZ G Water

Settlements

- city

town

o village

F9:1 Fig. 9. LCZ map of Kyiv with locations of settlements according to OSM. () OSM contributors.

However, both external datasets have their own errors so agreement between them is subject to some uncertainty. The illustrative examples (Fig. 5) showed that a comparison with external datasets should be treated with appropriate caveats. Comparison with in-situ temperature measurements and thermal remote sensing may be other ways to help vali- 481 date the classification. Validation is clearly an area that will 482 require more attention in the future if LCZs are to be used 483 with confidence in urban climate modeling or as inputs to other 484 applications. 


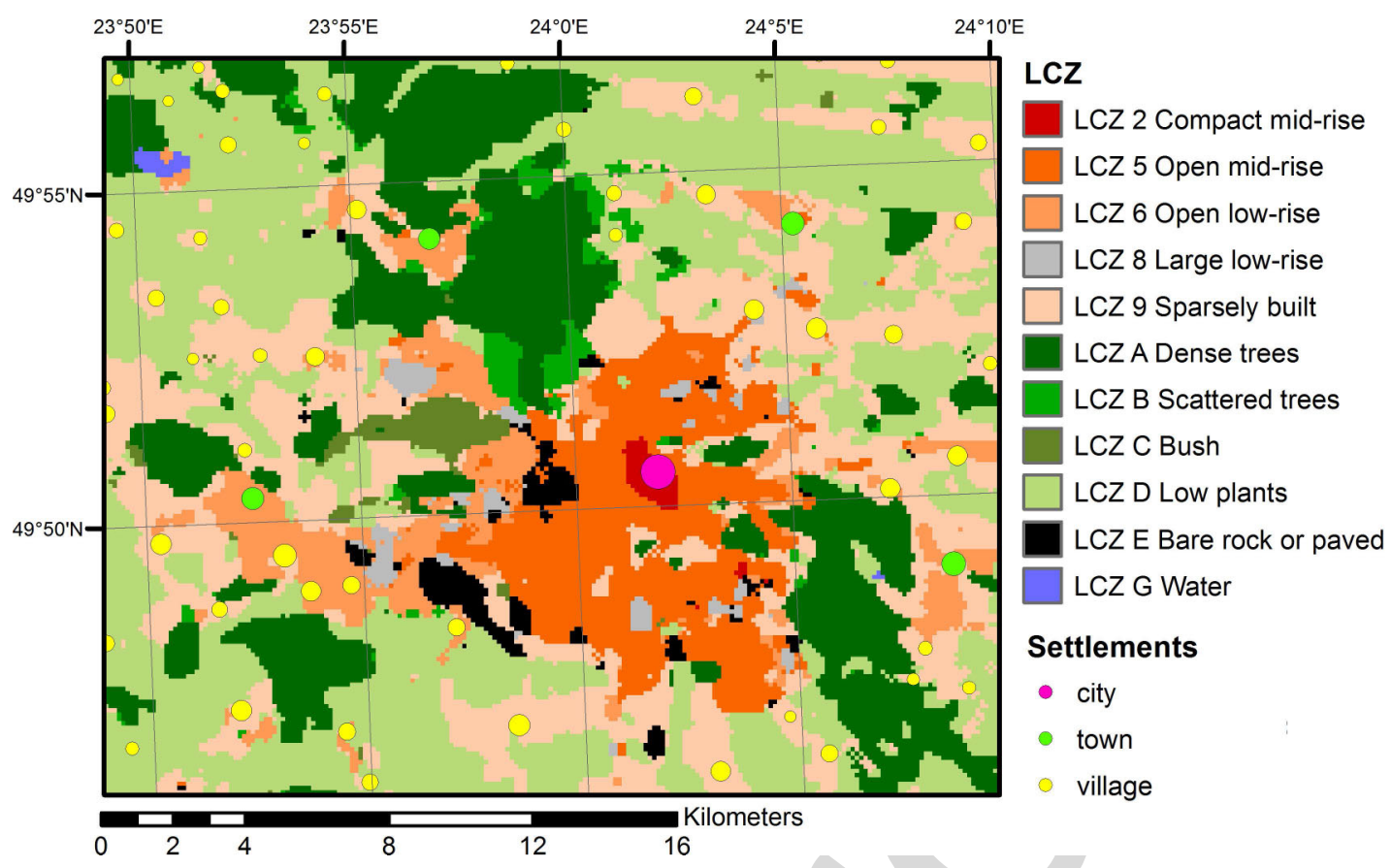

F10:1 Fig. 10. LCZ map of Lviv with locations of settlements according to OSM. ( ) OSM contributors.

T11:1 $\mathrm{T} 11: 2$ $\mathrm{T} 11: 3$
TABLE XI

COMPARISON OF City, TOWN, AND VILLAGE LOCATIONS From OSM IN RELATION TO THE LCZS FOR KYIV AND LVIV

\begin{tabular}{|c|c|c|c|c|c|c|}
\hline \multirow{2}{*}{ LCZ } & \multicolumn{2}{|c|}{ City } & \multicolumn{2}{c|}{ Town } & \multicolumn{2}{c|}{ Village } \\
\cline { 2 - 7 } & Kyiv & Lviv & Kyiv & Lviv & Kyiv & Lviv \\
\hline 2 & 1 & 1 & 0 & 0 & 0 & 0 \\
\hline 4 & 0 & N/A & 6 & N/A & 1 & N/A \\
\hline 5 & 0 & 0 & 0 & 1 & 0 & 0 \\
\hline 6 & 0 & 0 & 6 & 1 & 21 & 5 \\
\hline 9 & 0 & 0 & 2 & 1 & 81 & 33 \\
\hline A & 0 & 0 & 0 & 1 & 1 & 0 \\
\hline B & 0 & N/A & 0 & N/A & 5 & N/A \\
\hline E & 0 & 0 & 1 & 0 & 27 & 13 \\
\hline Total & 1 & 1 & 15 & 4 & 136 & 51 \\
\hline
\end{tabular}

\section{CONCLUSION}

In this paper, we applied a methodology for LCZ classification as first outlined in [11] in order to assess the transferability of this concept to two cities in the same climatic zone but that are quite different in urban form and topography, i.e., Kyiv and Lviv. The results demonstrated that LCZs are a generically applicable, culturally neutral classification for urban areas that allowed these cities to be compared in a standardized way. To a certain degree, the heterogeneous versus more homogenous pattern of LCZs in Kyiv and Lviv, respectively, does tell us something about the way cities are organized and could form a framework for further explanation of the patterns of urban form. However, we recognize that these cities and others classified in [12] are in the Global North so we need to further test the classification in cities located in the Global South before we can adequately assess transferability. Some efforts have already been made in this direction with the classification of Khartoum [13].

The workflow in [11] was also extended to consider different methods of validation, in particular validation using an independent dataset and comparison with other sources of information, i.e., OSM and the GlobeLand30 land cover product. The maps 507 will continue to be improved in those areas where confusion 508 between LCZs persists and then contributed to the WUDAPT 509 initiative, which has the overarching goal of creating LCZ clas- 510 sifications for all major cities globally. It will be possible to 511 visualize and download the data for urban climate modeling 512 purposes or for use in many other types of applications that 513 require a detailed delineation of the urban landscape. LCZs 514 will also form the basis of a sampling framework for collecting 515 more detailed information about the urban form and function of 516 cities in the future [4], [24]. More information can be found at: 517 http://www.wudapt.org.

\section{REFERENCES}

[1] I. D. Stewart and T. R. Oke, "Local climate zones for urban temperature 520 studies," Bull. Amer. Meteorl. Soc., vol. 93, no. 12, pp. 1879-1900, May 521 2012.

[2] T. R. Oke, "The energetic basis of the urban heat island," Q. J. R. 523 Meteorol. Soc., vol. 108, no. 455, pp. 1-24, Jan. 1982.

[3] European Environment Agency, Urban Atlas. Copenhagen, Denmark: 525 Copenhagen, 2010.

[4] L. See et al. "Developing a community-based worldwide urban mor- 527 phology and materials database (WUDAPT) using remote sensing and 528 crowdsourcing for improved urban climate modelling," presented at the 529 Joint Urban Remote Sensing Event (JURSE), Lausanne, Switzerland, 530 2015.

[5] J. Ching et al., "WUDAPT: Facilitating advanced urban canopy model- 532 ing for weather, climate and air quality applications," in Proc. IEEE 94th 533 Amer. Meteorol. Soc. Annu. Meeting, Atlanta, GA, USA, 2014, pp. 1-7 534 [Online]. Available: https://ams.confex.com/ams/94Annual/webprogram/ 535 Paper236443.html.

[6] M. Voltersen, C. Berger, S. Hese, and C. Schmullius, "Object-based land 537 cover mapping and comprehensive feature calculation for an automated 538 derivation of urban structure types at block level," Remote Sens. Environ., 539 vol. 154, pp. 192-201, Nov. 2014.

[7] M. Bochow, H. Taubenbock, K. Segl, and H. Kaufmann, "An automated 541 and adaptable approach for characterizing and partitioning cities into 542 urban structure types," in Proc. 2010 IEEE Int. Geosci. Remote Sens. 543 Symp. (IGARSS), Honolulu, HI, USA, Jul. 25-30, 2010, pp. 1796-1799, 544 doi: 10.1109/IGARSS.2010.5652972. 
[8] I. Walde, S. Hese, C. Berger, and C. Schmullius, "From land cover-graphs to urban structure types," Int. J. Geogr. Inf. Sci., vol. 28, no. 3, pp. 584 609, Mar. 2014.

[9] S. E. Gill, J. F. Handley, A. R. Ennos, S. Pauleit, N. Theuray, and S. J. Lindley, "Characterising the urban environment of UK cities and towns: A template for landscape planning," Landscape Urban Plann., vol. 87, no. 3, pp. 210-222, Sep. 2008.

[10] S. Pauleit and F. Duhme, "Assessing the environmental performance of land cover types for urban planning," Landscape Urban Plann., vol. 52, no. 1, pp. 1-20, Nov. 2000.

[11] B. Bechtel and C. Daneke, "Classification of local climate zones based on multiple earth observation data," IEEE J. Sel. Topics Appl. Earth Observ. Remote Sens., vol. 5, no. 4, pp. 1191-1202, Aug. 2012.

[12] B. Bechtel et al., "Mapping local climate zones for a worldwide database of the form and function of cities," ISPRS Int. J. Geo-Inf., vol. 4, no. 1, pp. 199-219, Feb. 2015.

[13] B. Bechtel, L. See, G. Mills, and M. Foley, "Classification of local climate zones using SAR and multi-spectral data in an arid environment," IEEE J. Sel. Topics Appl. Earth Observ. Remote Sens., 2016, to be published.

[14] M. F. Hamm, Kiev: A Portrait, 1800-1917. 4: printing and 1: paperback printing, Princeton, NJ, USA: Princeton Univ. Press, 1993.

[15] Kiev Department of Statistics, "Population," 2014 [Online]. Available: http://kievobl.ukrstat.gov.ua/content/.

[16] Wikipedia, "List of European Cities by Population," 2015 [Online]. Available: https://en.wikipedia.org/wiki/.

[17] Wikipedia, "Kiev," 2015 [Online]. Available: https://en.wikipedia.org/ wiki/Kiev.

[18] Wikipedia, "Lviv," 2015 [Online]. Available: https://en.wikipedia.org/ wiki/Lviv.

[19] Lviv Ecotour, "Why Lviv has no street grid," West Ukraine Genealogy, Tours and Transport, 2016 [Online]. Available: http://lvivecotour.com/ why-lviv-has-no-street-grid/.

[20] Lviv Department of Statistics, "Population," 2014 [Online]. Available: http://www.lv.ukrstat.gov.ua/eng/main_eng.php.

[21] J. Chen et al., "Global land cover mapping at $30 \mathrm{~m}$ resolution: A POK-based operational approach," ISPRS J. Photogramm. Remote Sens., vol. 103, pp. 7-27, May 2015.

[22] F. Ramm, J. Topf, and S. Chilton, OpenStreetMap: Using and Enhancing the Free Map of the World. Cambridge, England: UIT Cambridge, 2011.

[23] O. Conrad et al., "System for automated geoscientific analyses (SAGA) v. 2.1.4," Geosci. Model Dev., vol. 8, no. 7, pp. 1991-2007, Jul. 2015.

[24] L. See et al., "Generating WUDAPT's specific scale-dependent urban modeling and activity parameters: Collection of level 1 and level 2 data," presented at the 9th International Conference of Urban Climate (ICUC9), Toulouse, France, 2015.

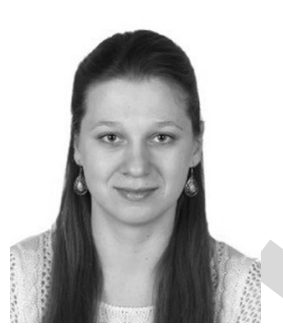

Olha Danylo received the M.Sc. degree in mathematical and computer modeling and the Ph.D. degree in mathematical simulation from Lviv Polytechnic National University, in 2012 and 2015, respectively.

She is a Research Scholar in the Ecosystems Services and Management (ESM) Program with the International Institute for Applied Systems Analysis (IIASA), Laxenburg, Austria. Her research interests include the use of GIS and machine-learning algorithms to analyze spatial and remote-sensing data, contributes to the science of urban climatology. which is aimed at improving land cover mapping and

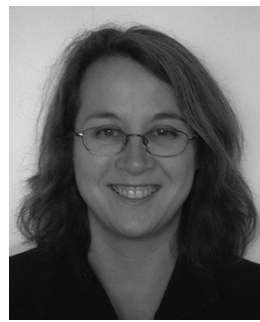

Linda See received the Ph.D. degree in spatial applications of fuzzy logic from the University of Leeds, Leeds, U.K., in 1999.

She is a Research Scholar in the ESM Program with the International Institute for Applied Systems Analysis, Laxenburg, Austria. She was a Senior Lecturer in Computational Geography and GIS for more than a decade with the University of Leeds. She spent one year at the Max Planck Institute for Atmospheric Sciences in Germany followed by four years with the Food and Agriculture Organization, Rome, Italy, working in agrometeorology and early warning for food security.
Dr. See is an active member of the Geo-Wiki Team and has worked on a 615 number of crowdsourcing aspects including quality issues, community build- 616 ing, and a branch of Geo-Wiki concerned with validation of urban land cover. 617 She is currently a Chair of the Working Group 1 of the EU COST network: 618 TD1202 Mapping and the Citizen Sensor.

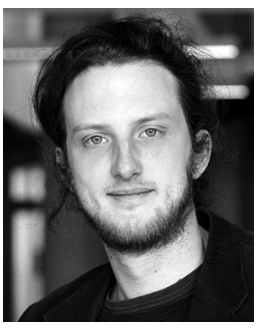

Benjamin Bechtel received the Ph.D. degree in geo- 620 sciences from the University of Hamburg, Hamburg, 621 Germany, in 2012.

$\mathrm{He}$ is a Research Associate with the Cluster 623 of Excellence CliSAP, University of Hamburg. His 624 research interests include urban remote sensing, in 625 particular the characterization of urban surfaces for 626 applications in urban climatology.

Dr. Bechtel is a Reviewer for numerous interna- 628 tional journals and Guest Editor for Remote Sensing 629 in the special issue "The Application of Thermal 630 Urban Remote Sensing to Understand and Monitor Urban Climates." He was 631 the recipient of the Dissertation Award 2013 for physical geography of the 632 Verband der Geographen an Deutschen Hochschulen (VGDH).

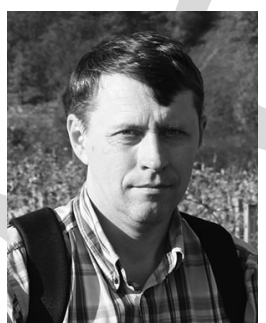

Dmitry Schepaschenko received the Engineer's 634 degree in forestry from Moscow State Forest 635 University, Mytischi, Russia, in 1988, the Ph.D. 636 degree in soil science from Dokuchaev Soil Science 637 Institute, Moscow, Russia, in 1993, and the Professor 638 degree in ecology from Moscow State Forest 639 University, in 2005

$\mathrm{He}$ is a Research Scholar in the ESM Program 641 with the International Institute for Applied Systems 642 Analysis, Laxenburg, Austria. He also holds a part- 643 time Professorial position at the Department of 644 Pedology with Moscow State Forest University. His research interests include 645 global and regional land cover, forest and biomass mapping, full carbon account 646 of Northern Eurasia, remote sensing applications, modeling of structure, pro- 647 ductivity and growth of forests, and adaptation and mitigation strategies under 648 global change.

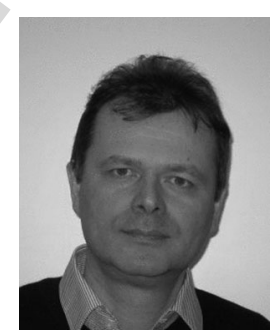

Steffen Fritz received undergraduate degree in 650 physics and geography from the University of 651 Tuebingen, Tuebingen, Germany, in 1995, the M.Sc. 652 degree in GIS from the University of Durham, 653 Durham, U.K., in 1996, and the Ph.D. degree in GIS 654 and wildland research from the University of Leeds, 655 Leeds, U.K., in 2001.

$\mathrm{He}$ is a Head of the Earth Observation Systems 657 (EOS) Group in the ESM Program with the 658 International Institute for Applied Systems Analysis, 659 Laxenburg, Austria. He is a Senior Expert in GIS, 660 remote sensing, data interoperability, land use and land cover as well as policy- 661 related land-use modeling. He has authored in the field of earth observation, 662 crowdsourcing, fuzzy logic, remoteness mapping, global and regional veg- 663 etation monitoring, crop yield and crop acreage estimation, and wild land 664 research.

Dr Fritz is a Coordinator of a European Research Council (ERC) grant 666 entitled "Harnessing the power of crowdsourcing to improve land cover and 667 land-use Information." $\mathrm{He}$ is the driving force behind Geo-Wiki, a tool for 668 visualization, crowdsourcing, and validation of land cover and is currently a 669 Co-Chair of the EU COST network: TD1202 Mapping and the Citizen Sensor. 670 